\title{
Comparing the Thermal Efficiency of Courtyard and Atrium
}

\author{
Mobina Baradaran Yazdi *,1, Hadi Bagheri Sabzevar *,2 \\ * Department of Architectural Engineering and Urbanism, Hakim Sabzevari University, Iran \\ ${ }^{1}$ Mobina_baradaran_y@yahoo.com \\ 2h.bagheri@hsu.ac.ir
}

\begin{abstract}
Most designers and energy resources managers today are concerned about the multiplicity of buildings in which energy considerations have not been taken into account. The result is the bioenvironmental and energy crises. Also, the uncontrolled consumption of energy in buildings is associated with both the risk of putting an end to non-renewable energy resources and an increase in the maintenance costs. Previous research suggests that turning courtyard into atrium can be an appropriate solution by lowering the wastage of thermal energy. In educational settings such as universities, the greenhouse effect of an atrium in cold seasons can be an appropriate alternative for keeping the adjacent spaces warm and lowering the use of thermal systems. The present study was conducted to determine the rate of decrease in thermal energy consumption by covering the courtyard using an energy simulator on the building of the faculty of engineering at Hakim Sabzevari University, Iran. In order to prevent the greenhouse effect of the atrium in warm seasons, skylights are installed for letting the air out. Based on the simulation of atrium and courtyard models, the results showed that the heating load of the courtyard model is much higher than the atrium model in winter. Consequently, the heating function of the Faculty building improved by $27 \%$ when converted to atrium model.
\end{abstract}

Keyword-Atrium, Courtyard, Energy use, Hakim University, Sabzevar

\section{INTRODUCTION}

The energy efficiency of built environment in urban areas plays an important part in lowering the problems of climate change, resource diminution, and environmental challenges at large [1]. Building energy consumption level will be on the rise in near future [2]. According to [3], due to higher contemporary living standards and rapid urbanization, the energy-consuming appliances such as air conditioners and urban building areas will lead to an increase in energy consumption by human beings [3]. In order to reduce the wastage of energy, transitional spaces are generally considered for receiving natural light and air [4-10]. Throughout the history, human beings have used such spaces for over 5000 years [11, 12], and different types of these have been introduced for various purposes. These spaces may include a multiplicity of spaces from a balcony and a corridor to a courtyard or an atrium.

Transition zones may be assumed as architectural spaces where the indoor and outside climate is moderated without applying HVAC systems. Consequently, those living in such buildings may experience the dynamic effects of changes in the outdoor climate. In addition, transitional spaces variously interact with the outdoor environment depending on the climate.

In a relative study, Aldawoud and Clark [13] searched the thermal performance of the same geometric proportions of atrium and courtyard for four diverse climate types; they concluded that courtyard displayed better for low rise buildings, but noticed the closed atrium much better for longer buildings. According to Aldawoud and Clark [13], the height of the building varies by parameters such as glazing type and climate type. Similarly, [14] examined the thermal performance of five different atrium types for four different climate types according to different skylight positions and tilted angles, and used two simulation programs to ensure the accuracy of their findings; then they calculated the solar intensities for different roof geometries. Ghaffar and colleagues' findings of the two simulation programs confirmed each other, and the solar intensities at the atrium surface significantly affected the atrium's roof geometry and skylight design. Also, Sher et al. [6] investigated energy savings achieved by using atrium in small houses by comparing the four basic atrium types with the non-atrium case in a residential building; the results of their study showed that the use of atrium increased the annual heating energy demand of the building, and reduced the annual cooling energy demand. Considering the total energy savings, a significant ratio of $15.7 \%$ was achieved annually. In another study, Aram and Alibaba [15] analyzed the optimal single-storey office building model with a corner atrium type according to four different atrium orientations and five different window opening ratios; their findings showed that for the Mediterranean climate, the atrium window opening rates and orientation may be used in bettering the user comfort and thermal efficiency performance during the year. Investigating the respective values for variables that affect the efficiency of the atrium in terms of thermal and daylight performance, Vethanayagam and Abu-Hijleh [16] found that by applying optimum values 
collectively for all variables, energy consumption can be minimized by approximately $20 \%$, irrespective of the number of floors.

Despite many studies on the thermal efficiency of atrium and courtyard and relevant variables, decision on covering the courtyard and turning it into an atrium (and determining the accurate efficiency of atrium) requires further research.

The present study was conducted to determine the rate of decrease in thermal energy consumption by covering the courtyard suing an energy simulator (i.e. Energy Plus) over the building of the Faculty of Engineering at Hakim Sabzevari University, Iran; and to help university officials in deciding to cover the courtyard.

\section{METHODOLOGY}

For investigating the energy performance of atrium and courtyard buildings, a building energy simulator (i.e. Energy Plus) was used. Building energy simulation provides a quick and easy estimate of the energy consumption in a given building, based on the corresponding climate and building characteristics. The building energy simulation is performed applying EnergyPlus simulation engine and OpenStudio SketchUp Plugin as an interface for EnergyPlus. This combination of software is chosen because of the reliability of EnergyPlus, which has been validated under the comparative Standard Method of Test for the Evaluation of Building Energy Analysis Computer Programs BESTEST/ASHRAE STD 140 [17], and is used by many researchers [18-22]. EnergyPlus calculates heating, cooling, lighting, ventilating, and other energy flows.

The following properties were implemented in EnergyPlus in order to investigate the energy consumption in the present study.

\section{A. Modelling and simulations}

The two buildings of the Engineering Faculty at Hakim Sabzevari University, Iran (one having a central, enclosed atrium with a skylight and the other having a central courtyard) were modeled in OpenStudio SketchUp Plugin. They both have the same geometrical proportion, length, width, and height. The courtyard model consisted of the four courtyard adjacent zones as shown in Fig. 1. Likewise, the atrium model included the four atrium adjacent zones ant the atrium zone. The central space area (courtyard and atrium) was $484 \mathrm{~m}^{2}(22 \mathrm{~m}$ length and $22 \mathrm{~m}$ width). In the adjacent spaces, the depth and floor height were $11 \mathrm{~m}$ and $4.5 \mathrm{~m}$, respectively. The total area in the two stories was measured at $1303 \mathrm{~m}^{2}$ and the internal environment of the four adjacent spaces was modeled as fully air-conditioned.

\begin{tabular}{|c|c|c|}
\hline $\begin{array}{c}\text { Dimensions and Geometry of } \\
\text { models by m }\end{array}$ & $\begin{array}{c}\text { Atrium model } \\
\text { Five thermal zones } \\
(\mathbf{N}, \mathbf{E}, \mathbf{S}, \mathbf{W})\end{array}$ \\
\hline
\end{tabular}

Fig. 1. The atrium and courtyard models with the same geometries and dimensions

\section{B. Simulation setup}

Design requirements including schedules were considered for the simulation process. Readily available weather data in the form of TRY was used for Sabzevar city. The simulation resolution was in 1-h increments, relying on weather data. The main focus of the simulation process was to evaluate the energy demand in the form of heating loads, cooling loads, and the total energy consumption with ideal air load system for the proposed models. Tables 1,2 below show the construction elements used. 
Table 1. constructions and Materials

\begin{tabular}{|c|c|}
\hline Structure & Materials (outside- inside) \\
\hline Floor & High weight concrete+ Mortar+ terrazzo \\
\hline Ceiling & Stucco+ Con-ceiling+ Light weight concrete+ Mortar+ terrazzo \\
\hline Roof & Stucco+ Con-ceiling+ Light weight concrete+ tar layer+ Mortar+ terrazzo \\
\hline Partition & Stucco+ Brick clay $(10 \mathrm{~cm})+$ Stucco \\
\hline Wall & Faced Brick+ Mortar+ Rock wool + Brick clay $(20 \mathrm{~cm})+$ Stucco \\
\hline Window & Transparent glass + Argon gas + Transparent glass \\
\hline Sky light & Transparent glass \\
\hline
\end{tabular}

Table 2. Physical and thermal properties of the hard materials used in simulation

\begin{tabular}{|c|c|c|c|c|c|}
\hline Materials & $\begin{array}{c}\text { Thickness } \\
(\mathbf{m})\end{array}$ & $\begin{array}{c}\text { Specific Heat } \\
(\mathbf{J} / \mathbf{k g k})\end{array}$ & $\begin{array}{c}\text { Solar } \\
\text { Absorptance }\end{array}$ & $\begin{array}{c}\text { Density } \\
(\mathbf{K g} / \mathbf{m 3})\end{array}$ & $\begin{array}{c}\text { Conductivity } \\
(\mathbf{W} / \mathbf{m k})\end{array}$ \\
\hline Stucco & 0.025 & 837.00 & 0.920 & 1858.00 & 0.69 \\
\hline Con-ceiling & 0.3 & 1113.39 & 0.500 & 428.75 & 1.00 \\
\hline Faced Brick & 0.10 & 900.00 & 0.500 & 1850.00 & 1.00 \\
\hline Brick clay & 0.100 & 790.00 & 0.500 & 783.00 & 0.525 \\
\hline Brick clay & 0.200 & 790.00 & 0.700 & 731.00 & 0.500 \\
\hline Concrete High weight & 0.100 & 837.00 & 0.700 & 2400.00 & 2.300 \\
\hline Light Weight Concrete & 0.100 & 900.00 & 0.700 & 1500.00 & 0.520 \\
\hline Mortar & 0.030 & 900.00 & 0.700 & 2240.00 & 1.800 \\
\hline Rock wool & 0.050 & 1170.00 & 0.500 & 80.00 & 0.040 \\
\hline Tar Layer & 0.003 & 836.00 & 0.900 & 2100.00 & 0.700 \\
\hline Terrazzo & 0.025 & 837.00 & 0.700 & 2400.00 & 2.00 \\
\hline Air wall & 0.010 & 1000.00 & 0.700 & 800.00 & 0.600 \\
\hline
\end{tabular}

Atrium and courtyard buildings, which have been simulated in this study, were assumed to have a constant $40 \%$ window-to-wall ratio on the facades of the building.

\section{Calculation of summer thermal comfort}

Thermal comfort temperature boundaries reflect the temperature range in the indoor environment which is assumed to be comfortable for users [23, 24]. Among all thermal comfort standards, the present study uses National Building Regulations of Iran for the calculations of summer and winter thermal comfort, in which the cooling and heating set-points are set to $28^{\circ} \mathrm{C}$ and $20^{\circ} \mathrm{C}$, respectively.

\section{Natural Airflow network in buildings}

In order to use natural ventilation in the courtyard model, the minimum temperature condition of $26^{\circ} \mathrm{C}$ was defined for all four-zone windows all year long; however, for the atrium model, three types of natural ventilation were considered.

1. For all environmental four-zone windows, the minimum temperature condition of $26^{\circ} \mathrm{C}$ was defined.

2. For all four-zone windows opening into the atrium for using the warm air during the cold season, the minimum temperature condition of $23^{\circ} \mathrm{C}$ was defined, provided that the atrium temperature is above $23^{\circ} \mathrm{C}$.

3. Being seasonally dependent, the skylight windows were wide open from April 30th to October 30th, providing free ventilation.

\section{DISCUSSION AND RESULTS}

After simulation, the output was obtained in Excel. Based on a monthly comparison of the heating and cooling curves of the atrium and courtyard models in winter, the heating of the courtyard model was much higher than that of the atrium model. Maximum and minimum differences of the heating load were in January (18.73 GJ) and May $(0.013 \mathrm{GJ})$, respectively. The cooling of the atrium model was higher than the courtyard model; maximum difference of the cooling was observed in May $(0.98 \mathrm{GJ})$. 


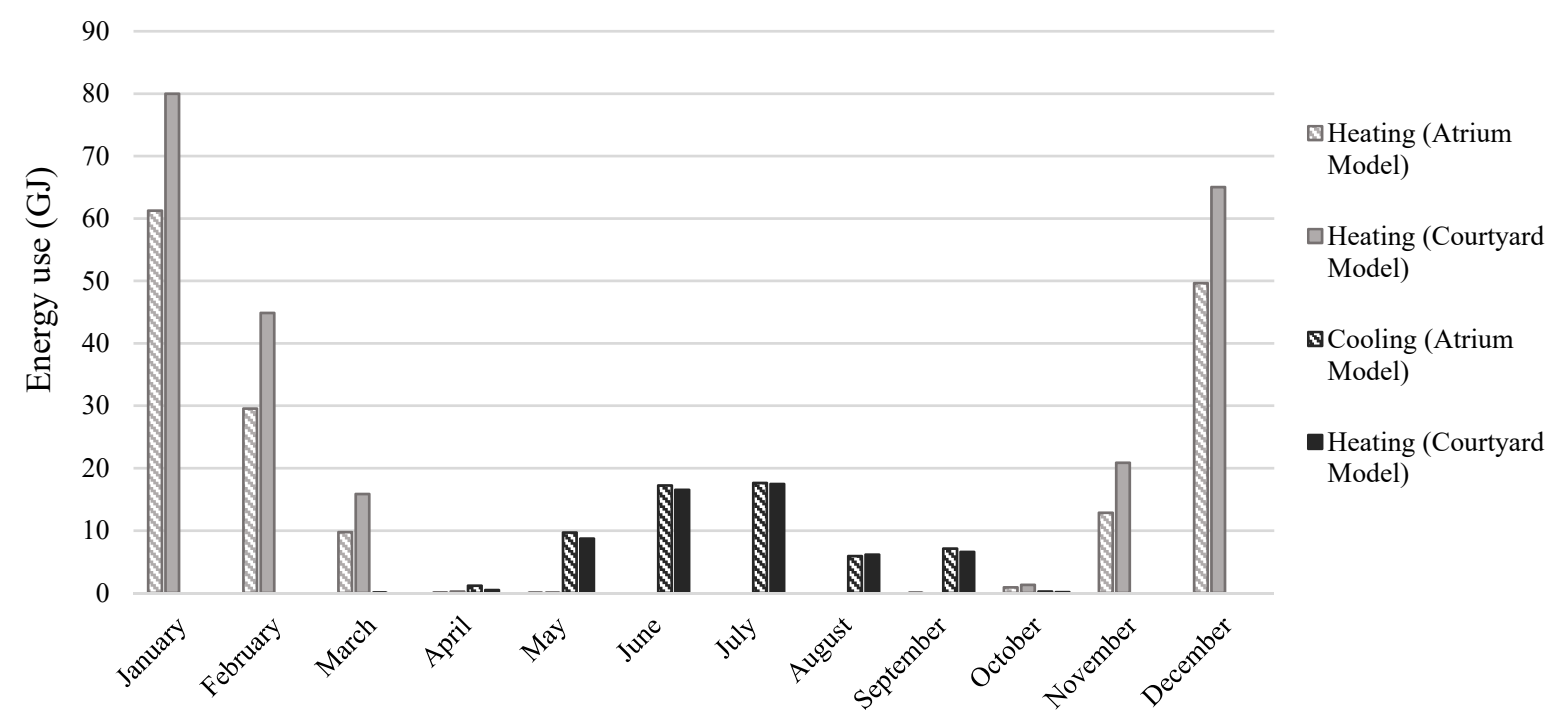

Fig. 2. Monthly heating and cooling of atrium and courtyard models

The annual comparison between the heating and cooling curves of the courtyard and atrium models displayed that the annual heating of the courtyard model was 23.81 GJ higher than that of the atrium model. Also, the annual cooling of the atrium model was 0.4 GJ higher than that of the courtyard model.

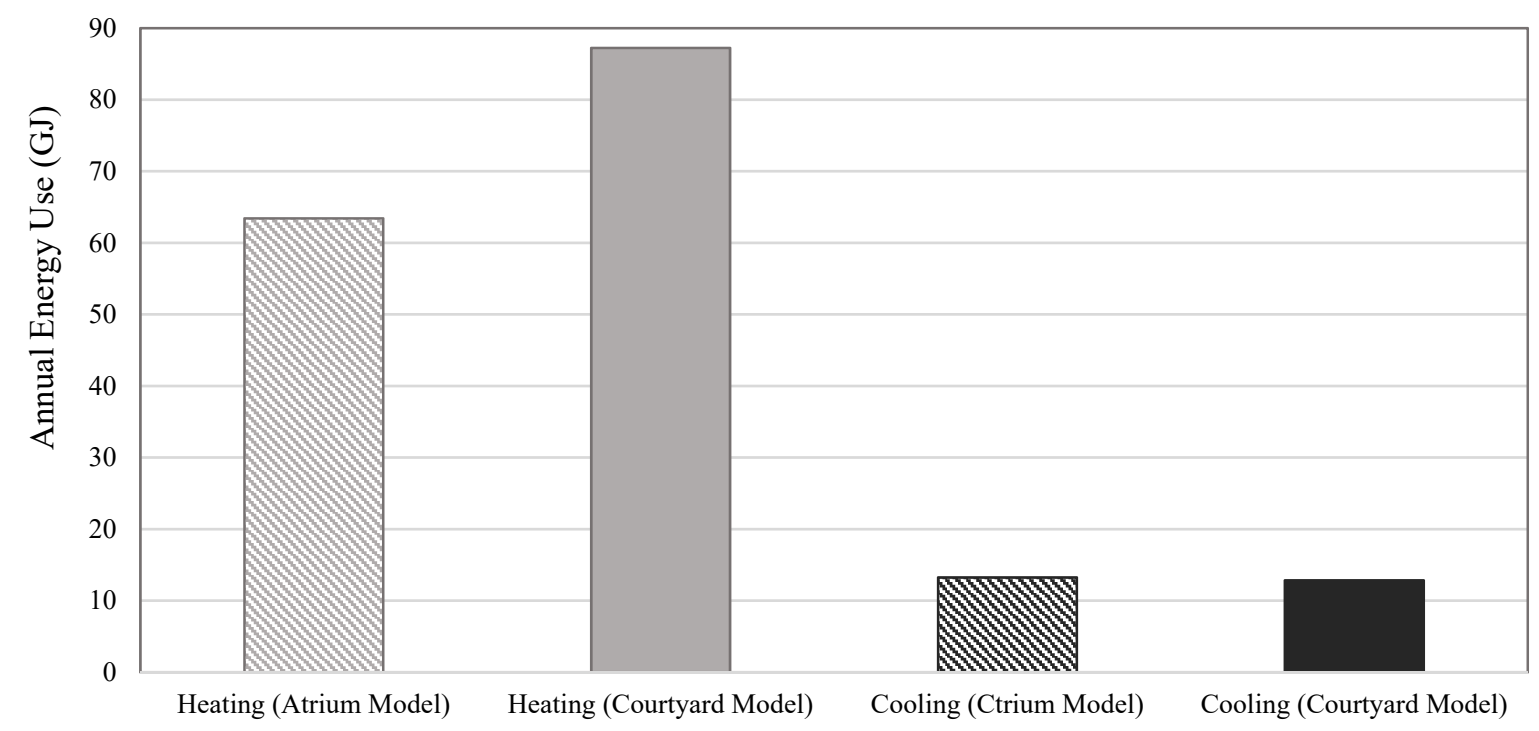

Fig. 3. The annual graphic representation of thermal and cooling load of the atrium and courtyard models

Then the mean temperature of the air and atrium zone during the first week in winter and summer were comparted. In summer, the temperature of air and atrium zones were the same due to atrium skylight opening. As shown in Figure 4, the atrium temperature during the first week of the summer (June 22-28) overlaps with the open air temperature. Therefore, the cooling energy consumption becomes roughly the same during summer in both atrium and courtyard models. 

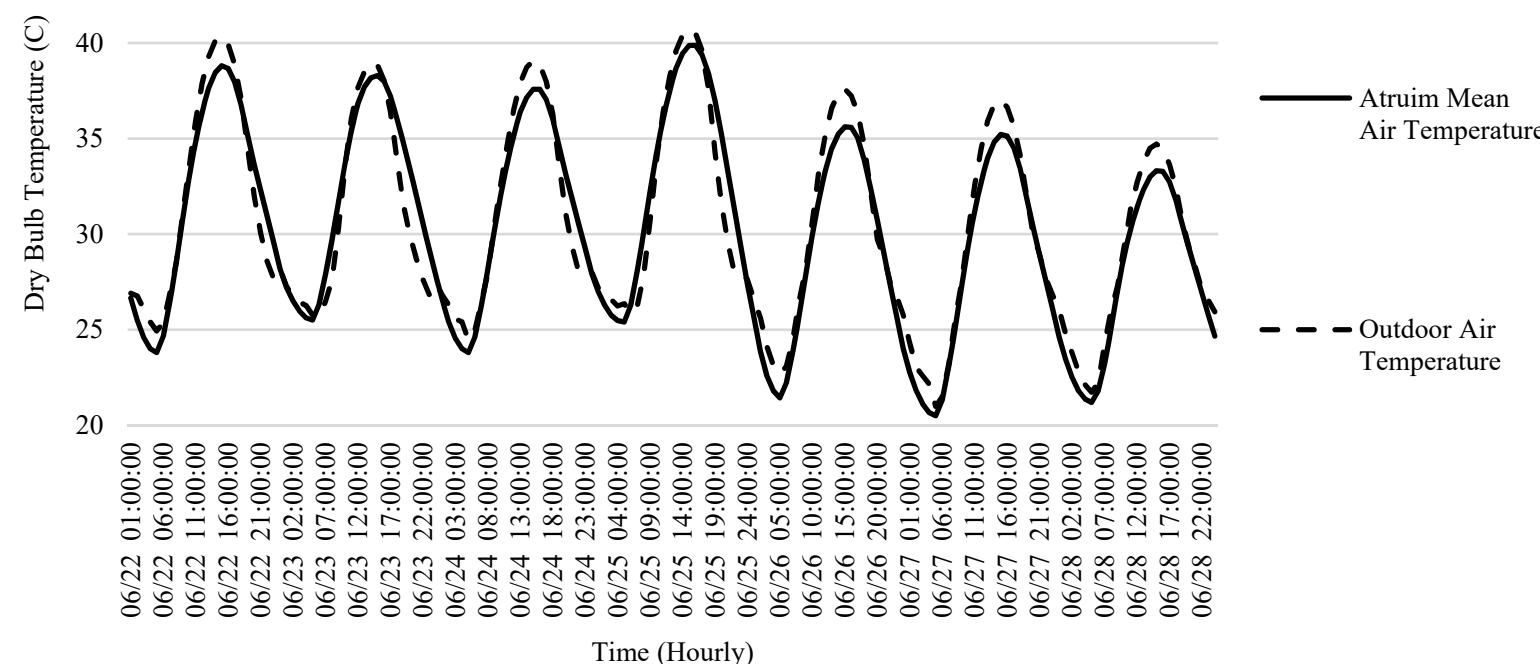

Time (Hourly)

Fig. 4. Mean air and atrium zone temperature in summer

On the other hand, the air and atrium zone temperatures were also compared during winter. As the skylight was closed in winter, a greenhouse effect is created. As shown in Figure 5, the atrium zone temperature during the first week of winter (December $22-28$ ) ranged from $10^{\circ} \mathrm{C}$ to $23^{\circ} \mathrm{C}$; however, the open air temperature ranged from $-5^{\circ} \mathrm{C}$ to $14^{\circ} \mathrm{C}$ during the same time interval. On average, the atrium zone temperature was approximately $15^{\circ} \mathrm{C}$ higher than the open air temperature in winter. The greenhouse effect of the atrium model in winter increase the atrium zone temperature and lowers the heating energy consumption.

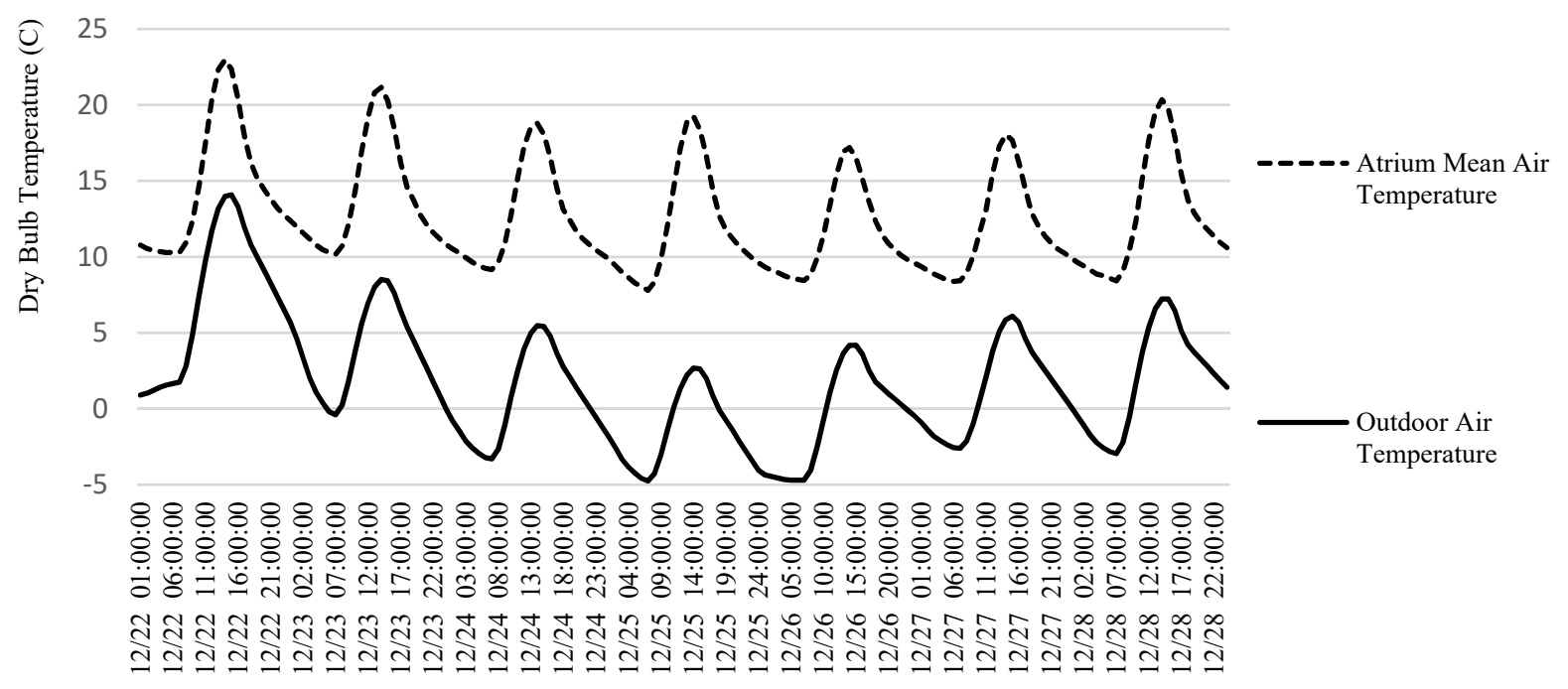

Time (Hourly)

Fig. 5. Mean air and atrium zone temperature in winter 


\section{Conclusion}

Comparing the thermal efficiency figures suggest that the atrium model provides a better thermal function in cold seasons than the courtyard model. The results showed that turning the courtyard into atrium decreased the heating load by $27 \%$. Also, the temperature of the adjacent spaces of atrium was $7^{\circ} \mathrm{C}$ higher than the corresponding temperature in courtyard. This decreases the use of heating systems and, accordingly, reduces the energy costs.

In order to prevent rising of temperature in summer, opening the skylight does not let detention of heat in atrium, and the creation of greenhouse effect. Consequently, the cooling of atrium increases by only $3 \%$ higher than courtyard model.

The findings of the present study, therefore, suggest that despite the better heating function of the faculty building courtyard in summer, the atrium model turns out to be more appropriate and more efficient than the courtyard model in cold seasons. We stress the findings here because the case of our study was the Faculty of Engineering, an educational building which holds more people in cold seasons than in summer.

\section{REFERENCES}

[1] Steemers, K.J.E. and buildings, Energy and the city: density, buildings and transport. 2003. 35(1): p. 3-14

[2] Yan-ping, F., W. Yong, and L.J.E.P. Chang-bin, Energy-efficiency supervision systems for energy management in large public buildings: Necessary choice for China. 2009. 37(6): p. 2060-2065.

[3] Cai, W., et al., China building energy consumption: situation, challenges and corresponding measures. 2009. 37(6): p. 2054-2059.

[4] Reynolds, J., Courtyards: aesthetic, social, and thermal delight. 2002: John Wiley \& Sons.

[5] Chun, C., A. Kwok, and A. Tamura, Thermal comfort in transitional spaces - basic concepts: literature review and trial measurement. Building and Environment, 2004. 39(10): p. 1187-1192.

[6] Pitts, A. and J.B. Saleh, Potential for energy saving in building transition spaces. Energy and Buildings, 2007. 39(7): p. 815-822.

[7] Aldawoud, A. and R. Clark, Comparative analysis of energy performance between courtyard and atrium in buildings. Energy and Buildings, 2008. 40(3): p. 209-214.

[8] Muhaisen, A.S.J.S.P.o.C.B.I.D.C.R., Using a New Computer Model, Solar Performance of Courtyard Buildings: In Different Climatic Regions, Using a New Computer Model. 2010.

[9] Ghaddar, N., K. Ghali, and S. Chehaitly, Assessing thermal comfort of active people in transitional spaces in presence of air movement. Energy and Buildings, 2011. 43(10): p. 2832-2842.

[10] Yang, X., Y. Li, and L. Yang, Predicting and understanding temporal 3D exterior surface temperature distribution in an ideal courtyard. Building and Environment, 2012.57: p. 38-48.

[11] Fathy, H., Natural energy and vernacular architecture. 1986.

[12] Oliver, P., Dwellings: the house across the world. 1987: Phaidon.

[13] Aldawoud, A., R.J.E. Clark, and Buildings, Comparative analysis of energy performance between courtyard and atrium in buildings. 2008. 40(3): p. 209-214.

[14] Ab Ghafar, N., et al., Evaluation of thermal and solar performance in atrium buildings using sequential simulation. 2019. 30(6): p. 969990.

[15] Aram, R. and H.Z.J.S. Alibaba, Thermal comfort and energy performance of atrium in Mediterranean climate. 2019. 11(4): p. 1213.

[16] Vethanayagam, V. and B.J.F.o.A.R. Abu-Hijleh, Increasing efficiency of atriums in hot, arid zones. 2019. 8(3): p. 284-302.

[17] Henninger, R. and M.J.G.A. Witte, EnergyPlus testing with ANSI/ASHRAE standard 140-2001 (BESTEST). 2004.

[18] Harmati, N. and Z. Magyar. Energy consumption monitoring and energy performance evaluation of an office building. in Proceeding of the Fifth German-Austrian IBPSA Conference BauSim. Aachen. 2014.

[19] Crawley, D.B., et al., EnergyPlus: creating a new-generation building energy simulation program. 2001. 33(4): p. 319-331.

[20] Kahsay, M.T., G. Bitsuamlak, and F. Tariku. Effect of localized exterior convective heat transfer on high-rise building energy consumption. in Building Simulation. 2020. Springer.

[21] Sabzevar, H.B., M.H. Ahmad, and A. Gharakhani. Courtyard geometry on solar heat gain in hot-dry region. in Advanced Materials Research. 2014. Trans Tech Publ.

[22] Sabzevar, H.B.J.J.o.E. and A. Sciences, Energy plus validation of a courtyard house in Yazd-Iran. 2016. 100(9): p. 2009-2013.

[23] Nicol, J.F. and M.A. Humphreys, Adaptive thermal comfort and sustainable thermal standards for buildings. Energy and Buildings, 2002. 34(6): p. 563-572.

[24] Taleghani, M., et al., A review into thermal comfort in buildings. Renewable and Sustainable Energy Reviews, 2013. 26: p. 201-215. 